\title{
In vitro chloroquine resistance for Plasmodium vivax isolates from the Western Brazilian Amazon
}

\author{
Yonne F Chehuan ${ }^{1}$, Monica RF Costa ${ }^{1}$, Jacqueline S Costa ${ }^{1}$, Maria GC Alecrim ${ }^{1}{ }^{2}$, Fátima Nogueira ${ }^{3}$, \\ Henrique Silveira ${ }^{3}$, Larissa W Brasil ${ }^{1,2}$, Gisely C Melo ${ }^{1,2}$, Wuelton M Monteiro ${ }^{1,2^{*}}$ and Marcus VG Lacerda $a^{1,2,4}$
}

\begin{abstract}
Background: Chloroquine $(\mathrm{CQ})$ and primaquine $(\mathrm{PQ})$ are still the drugs of choice to treat Plasmodium vivax malaria in many endemic areas, Brazil included. There is in vivo evidence for the P. vivax resistance to CQ in the Brazilian Amazon, where the increase in the proportion of $P$. vivax malaria parallels the increase of unusual clinical complications related to this species. In this study, in vitro CQ and mefloquine (MQ)-susceptibility of $P$. vivax isolates from the Western Brazilian Amazon was tested using the double-site enzyme-linked lactate dehydrogenase immunodetection (DELI) assay.

Methods: A total of 112 P. vivax isolates were tested in vitro for CQ-susceptibility and out of these 47 were also tested for MQ-susceptibility. The DELI assay was used to detect $P$. vivax growth at 48-hour short-term culture in isolates with ring stages ranging from 50 to $70 \%$. Each isolate was tested in triplicate and geometric means of IC50's was obtained. Nineteen isolates were genetically characterized for pvdhfr, pvmrp 1, pvmdrl and pvdhps candidate genes likely related to CQ resistance ( 10 with IC50<40 nM and 9 with IC50 >100 nM).
\end{abstract}

Results: Twelve out of 112 isolates were considered resistant to CQ, resulting in 10.7\% (IC95\% 5.0-16.4), while 3 out of 47 (6.4\%; IC95\% 0.0-12.8) were resistant to MQ. A discrete correlation was observed between IC50's of CQ and MQ (Spearman=0.294; $p=0.045$ ). For pvdhps gene, a non-synonymous mutation was found at codon $382(S \rightarrow C)$ in 5/8 CQ-sensitive samples and 1/9 CQ-resistant samples ( $p=0.027)$. The other molecular markers were not associated to CQ-susceptibility.

Conclusions: In vitro CQ-resistance estimated in this study, estimated by the DELI test, was very similar to that observed in clinical trials, suggesting that in vitro procedures developed by capable local laboratories are useful in the surveillance of CQ-resistance in the Amazon; concurrent Amazon P. vivax strains with both CQ and MQ resistance may be common; and a non-synonymous mutation at pvdhps codon $382(S \rightarrow C)$ was associated to in vitro susceptibility to $C Q$, needing further studies to be confirmed.

Keywords: Malaria, Plasmodium Vivax, Chloroquine, Mefloquine, Resistance, Treatment

\section{Background}

Plasmodium vivax remains more widely distributed than Plasmodium falciparum and is a potential cause of morbidity and mortality amongst the 2.85 billion people living at risk of infection, the majority of whom are in the tropical belt of Central and Southeastern Asia and Latin America [1]. In Brazil, P. vivax is responsible for more

\footnotetext{
* Correspondence: wueltonmm@ibest.com.br

'Fundação de Medicina Tropical Dr. Heitor Vieira Dourado, Av. Pedro Teixeira, 25, Dom Pedro, Manaus, AM 69040-000, Brazil

${ }^{2}$ Universidade do Estado do Amazonas, Av. Pedro Teixeira, 25, Dom Pedro, Manaus, AM 69040-000, Brazil

Full list of author information is available at the end of the article
}

than $80 \%$ of the cases in the last years [2]. In this country, the increase in the proportion of $P$. vivax malaria parallels the increase in the frequency of unusual clinical complications in P. vivax-infected patients [3]. Chloroquine $(\mathrm{CQ})$ and primaquine $(\mathrm{PQ})$ are still the drugs of choice to treat vivax malaria in many endemic areas, Brazil included. The simultaneous occurrence of severe vivax disease and CQ-resistance in some countries has raised the question of a possible association between severity and resistance [4]. CQ-resistance actually has been reported in Brazil almost at the same time as clinical severity [5].

\section{Biomed Central}


There is in vivo evidence for the P. vivax CQresistance in the Brazilian Amazon. In this region, the resistance to CQ was firstly reported in Manaus in 1999 [5]. More recent data from studies conducted in the RAVREDA multicenter study (Amazonian Network for Surveillance for Resistance to Antimalarial Drugs) with a proper follow-up of patients exclusively using CQ and in whom drug plasma concentration was evaluated, seem to confirm such an observation [5]. However, since CQ plus $P Q$, the drug association used for the radical cure of $P$. vivax infection, has a synergistic action [6], further studies are needed to evaluate the contribution of CQ by itself for the effectiveness of the drug association, before any definitive conclusion can be proposed.

In vitro surveillance of anti-malarials resistance is largely used in P. falciparum with public health purposes, however $P$. vivax can grow only to a certain extent under in vitro conditions, with a very low reinvasion rate, what poses technical limitations to the routine use of this approach. The first in vitro $P$. vivax short-term culture was performed in 1974 [7], but more recent publications have presented reproducible results based on the WHO microtest using quantification of schizont maturation [8]. The method is cheap, however it is time-consuming since slides from the drug-free well have to be made every 6 hours trying to achieve the moment when there is schizonts maturation of $40 \%$. Even demanding monoclonal antibodies, what makes it more expensive, the double-site Plasmodium lactate dehydrogenase (LDH) antigen capture enzyme-linked immunosorbent assay (DELI) [9] quantifies the total pLDH produced by maturing stages, and can be performed in 48 hours after the beginning of the culture, avoiding sequential slides reading. The aim of this study was to estimate the in vitro CQ-susceptibility of $P$. vivax isolates from the Western Brazilian Amazon using the DELI assay.

\section{Methods}

\section{Site of study and patients}

The study was performed from December 2007 to July 2008 in the Fundação de Medicina Tropical Dr. Heitor Vieira Dourado (FMT-HVD), which reports $30 \%$ of all the malaria cases in Manaus $\left(03^{\circ} 06^{\prime} \mathrm{S}, 60^{\circ} 01^{\prime} \mathrm{W}\right)$. Patients living in the urban or peri-urban areas of this city with uncomplicated $P$. vivax malaria confirmed by a thick blood smear (TBS) were randomly selected in the outpatient clinics, from which epidemiological and clinical history was fully obtained. Parasite densities with differential counting of rings, trophozoites and schizonts were estimated by experienced microscopists, by counting the number of parasites in 200 leukocytes in high magnification fields, and the number of leukocytes $/ \mathrm{mm}^{3}$. The study included patients of both sexes, aged 12-60 years, presenting blood parasite density from 250 to 100,000 parasites $/ \mathrm{mm}^{3}$ and axillary temperature $\geq 37.5^{\circ} \mathrm{C}$ or history of fever in the last 48 hours. The major exclusion criterion was the use of anti-malarials in the previous 60 days. Due to the selective action of CQ upon young $P$. vivax trophozoites (rings) [10], only samples with ring stages ranging from $50-70 \%$ at the initial counting were analysed in this study.

\section{In vitro determination of susceptibility to drugs}

Blood samples were collected in on Vacutainer (Becton Dickinson $^{\oplus}$, Oxnard, CA) EDTA tubes prior to patient treatment. CQ sulfate and MQ hydrochloride were obtained from Sigma-Aldrich ${ }^{\oplus}$. Isolates from the same outpatient clinics were randomly selected (47 were tested for CQ and MQ susceptibility and additional 65 samples were tested only for CQ). The blood samples were washed twice with a solution of RPMI-1640 Medium $\left(\mathrm{Gibco}^{\oplus}\right)$ and then one time with culture complete medium. The blood samples were then resuspended in the complete culture medium to obtain a $1.5 \%$ haematocrit. Finally, $200 \mu \mathrm{L}$ of this suspension were distributed to each well in the anti-malarial predosed plates. The plates were systematically incubated for $48 \mathrm{~h}$ at $37^{\circ} \mathrm{C}\left(5 \% \mathrm{CO}_{2}, 5 \% \mathrm{O}_{2}\right.$ and $\left.90 \% \mathrm{~N}_{2}\right)$ and were immediately frozen at $-20^{\circ} \mathrm{C}$ until the DELI test was performed with many samples at the same time. Only cultures with viable schizonts at 48 hours were considered valid. For the DELI test, plates were frozen and thawed three times to haemolyse the culture and release pLDH [9]. Each isolate was tested in triplicate and geometric means of IC50's was obtained. IC50 threshold criterion for resistance to $C Q$ or $M Q$ was similar to that described elsewhere [9]. Dd2 and 3D7 P. falciparum clones were used as controls.

\section{Molecular characterization}

Nineteen isolates were genetically characterized for a few candidate genes linked to CQ resistance (10 with IC50<40 $\mathrm{nM}$ and 9 with IC50 >100 nM). Whole DNA extraction was carried out using a QIAamp ${ }^{\circ}$ DNA Mini Kit (QIAGEN ${ }^{\circ}$, Germany) according to the manufacturer's protocol. PCR primers and different reaction conditions used to amplify $P$. vivax dihydrofolate reductase (pvdhfr), multidrug resistance-associated protein 1 (pvmrp1), multidrug resistance 1 (pvmdr-1) locus, and dihydropteroate synthase ( $p v d h p s)$ gene sequences were made as previously described [11-16] (Additional file 1). Briefly, after initial denaturing at $94^{\circ} \mathrm{C}$ for 2 minutes, the samples were submitted to 35 cycles $\left(94^{\circ} \mathrm{C}\right.$ for 1 minute more, $58^{\circ} \mathrm{C}$ for 30 seconds, and $72^{\circ} \mathrm{C}$ for 1 minute), with a final extension at $72^{\circ} \mathrm{C}$ for 10 minutes. For each fragment, PCR products were visualized by $1 \%$ agarose gel electrophoresis stained with ethidium bromide to confirm single band. DNA concentration was measured by NanoDrop ${ }^{\circ}$ 
2000 (Thermo Scientific ${ }^{\circ}$ ). Sequencing reactions were carried out using an ABI 3130xl genetic analyzer (Applied Biosystems ${ }^{\circ}$, USA) as specified by manufacturer's protocol.

\section{Data analysis}

IC50 was calculated in the software Analysis of Malaria In Vitro Drug Sensitivity Data (HN-NonLin V 1.05 Beta ${ }^{\circ}$. Correlation between CQ and MQ IC50 was calculated through Pearson test. Fisher's test was employed to evaluate the association between point mutations and CQ-resistance. Analysis was performed using SPSS software for Windows (version 16; SPSS, Inc., Chicago, $\mathrm{IL}^{\circ}$ ). $\mathrm{P}<0.05$ was considered significant.

\section{Ethical procedures}

Collection of human samples and all study procedures were approved by the Ethical Review Committee of Fundação de Medicina Tropical Dr. Heitor Vieira Dourado (protocol number 1850/2007). Written informed consent was obtained from all the participant patients. All malaria cases were treated according to the Brazilian Ministry of Health's National guidelines, with CQ and PQ.

\section{Results}

Twelve out of 112 isolates were considered resistant to CQ, resulting in $10.7 \%$ (CI95\% 5.0-16.4) of CQresistance, while three out of 47 (6.4\%) (CI95\% 0.0-12.8) were resistant to MQ (Figure 1). A discrete correlation was observed between IC50's of CQ and MQ (Spearman=0.294; $\mathrm{p}=0.045$ ) (Figure 2).

As seen in the Table 1, for pvdhps gene, a nonsynonymous mutation at codon $382(\mathrm{~S} \rightarrow \mathrm{C})$ was found in 5/8 samples in vitro sensitive and $1 / 9$ samples in vitro resistant to $\mathrm{CQ}(\mathrm{p}=0.027)$. The other molecular markers were not associated to CQ susceptibility.

\section{Discussion}

Plasmodium vivax in vitro CQ-resistance levels in Latin America are unknown. In 2007, the proper 28 days follow-up of 109 patients with $P$. vivax prescribed only with CQ lead to the unexpected confirmation of $10.1 \%$ of resistance after plasmatic drug dosage [17], a rate very similar to that obtained from this study, suggesting that in vitro procedures developed by capable local laboratories are useful to the surveillance of CQ-resistance in the Amazon.

An interesting finding of this study was the concurrent resistance to both $\mathrm{CQ}$ and $\mathrm{MQ}$ within $P$. vivax strains from Amazon. In this region, a CQ-resistance rate of around $10 \%$ requires the evaluation of alternative drugs such MQ. Although MQ was thought to be a useful alternative treatment for $P$. vivax malaria in [18] and indirect evidence suggested that this drug may be

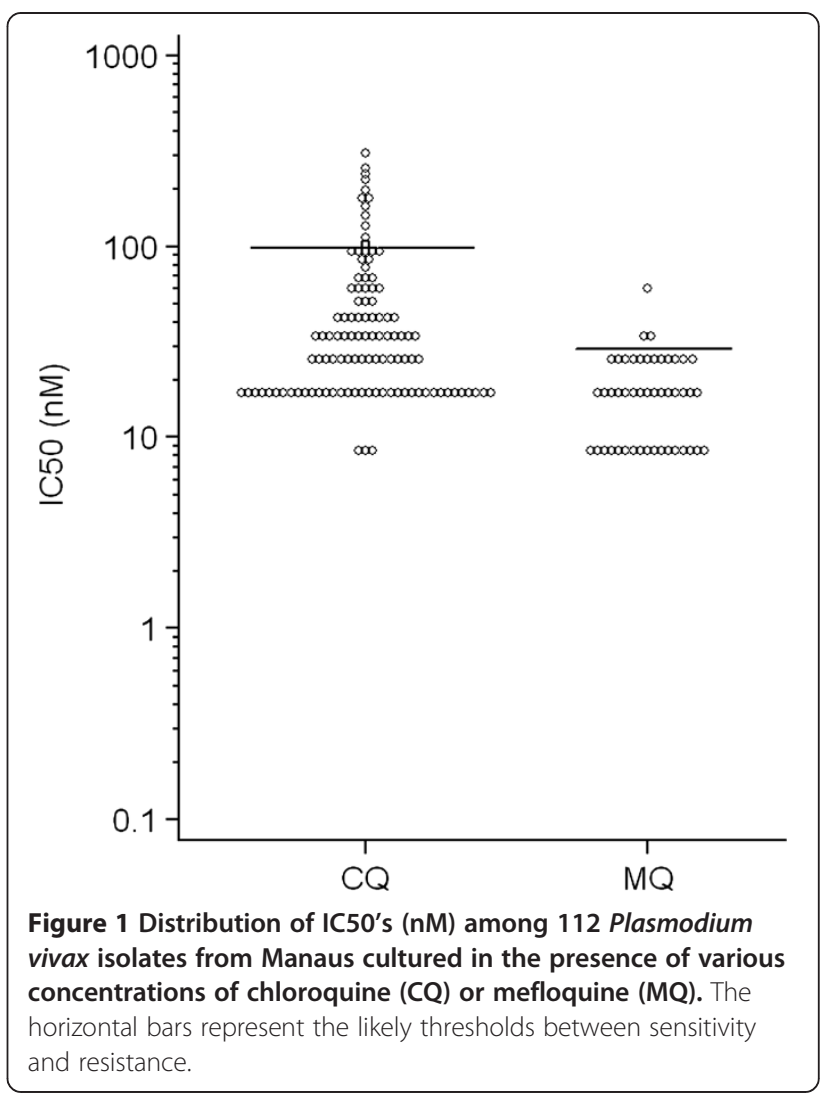

efficacious against CQ-resistant $P$. vivax in Indonesian New Guinea [19], there is no previous information from Latin America supporting these data. In 1999, Alecrim et al. [5] reported a case of a patient with $P$. vivax malaria who showed resistance to chloroquine and

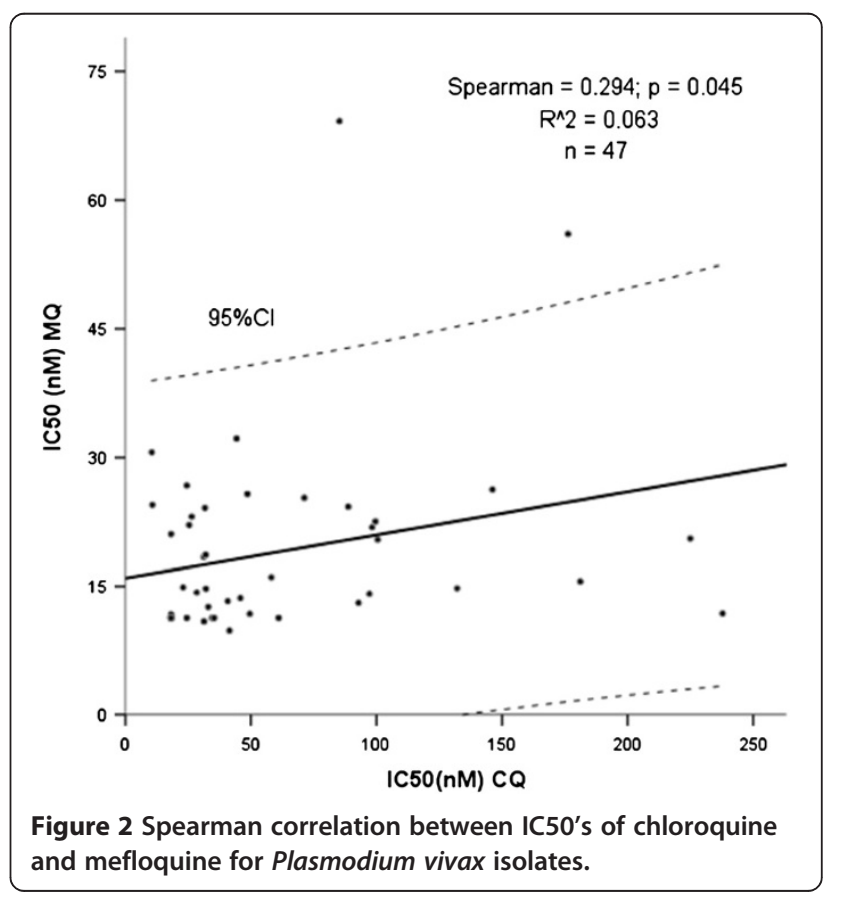




\begin{tabular}{|c|c|c|c|}
\hline Gene/Polymorphisms & $\begin{array}{l}\text { Sensitive } \\
\text { samples }\end{array}$ & $\begin{array}{l}\text { Resistant } \\
\text { samples }\end{array}$ & $\mathrm{p}$-value \\
\hline \multicolumn{4}{|l|}{ Pvdhfr } \\
\hline 58 & $7 / 10(70 \%)$ & 8/9 (88.9\%) & 0.313 \\
\hline 117 & $8 / 10(80 \%)$ & 8/9 (88.9\%) & 0.596 \\
\hline 173 & $1 / 10(10 \%)$ & 0/9 (0\%) & 0.330 \\
\hline \multicolumn{4}{|l|}{ pvmrp1 } \\
\hline 1282 & 9/9 (100\%) & $7 / 7(100 \%)$ & NS \\
\hline 1393 & 9/9 (100\%) & $7 / 7(100 \%)$ & NS \\
\hline 1419 & $4 / 9(44.4 \%)$ & $2 / 7(28.6 \%)$ & 0.515 \\
\hline 1478 & $10 / 10(100 \%)$ & 9/9 (100\%) & NS \\
\hline 1586 & $2 / 10(20 \%)$ & $2 / 9(22.2 \%)$ & 0.906 \\
\hline \multicolumn{4}{|l|}{ pvmdr1 } \\
\hline 908 & $1 / 10(10 \%)$ & $1 / 9(11.1 \%)$ & 0.937 \\
\hline 958 & $10 / 10(100 \%)$ & 8/9 (8.9\%) & 0.279 \\
\hline \multicolumn{4}{|l|}{ Pvdhps } \\
\hline 205 & 10/10 (100\%) & 9/9 (100\%) & NS \\
\hline 382 & $5 / 8(62.5 \%)$ & $1 / 9(11.1 \%)$ & 0.027 \\
\hline 383 & 0/8 (0\%) & $1 / 9(11.1 \%)$ & 0.331 \\
\hline
\end{tabular}

NS not significant.

mefloquine in the Brazilian Amazon region. CQ and MQ-resistance overlap have also had commonly reported from Thailand [20]. Nomura [21] pointed to different mechanisms of resistance between the two species, however some data including results presented here show that caution is required.

Among the isolates with IC50 defined, 19 have been genetically characterized (10 with IC $50<40 \mathrm{nM}$ and nine with IC50 >100 nM). For pvdhps gene, a nonsynonymous mutation was found at codon $382(\mathrm{~S} \rightarrow \mathrm{C})$ in 5/8 samples in vitro sensitive and $1 / 9$ samples in vitro resistant $(\mathrm{p}=0.027)$. It is known that the spread of sulphadoxine-pyrimethamine in $P$. falciparum exerted selective pressure for $p v d h p s$ mutations in $P$. vivax. Molecular studies on a population basis for $P$. falciparum have demonstrated that patients who were infected with parasites that carried this mutation may not respond to treatment [14], but when the parasite carries highly mutant versions of $p v d h p s$ and $p v d h f r$ genes, clinical effectiveness is compromised [22]. Another study showed that resistance-conferring mutations were not found in pvdhps [23]. The other genetic markers were not associated with drug response. Suwanarusk et al. [24] studying the same gene, found that CQ IC50 was significantly higher in P. vivax isolates carrying the Y976F mutation than in isolates with the wild-type allele. Ranjitkar et al. [25] found that the low resistance to CQ was due to the low prevalence of mutation Y976F in pvmdr1 (5\%). However, most studies did not find any association between mutation in the pvmdr-1 gene and CQ-resistance corroborating these results $[16,21,26,27]$.

Major limitations of this study were: (1) the small number of samples; (2) the lack a standard cut-off IC50 for the characterization of resistance in Latin American samples; (3) DELI test is a less time-consuming test due to the detection of pLDH in 48-hour culture plates, however it was never validated as compared to the microscopy test; (4) in vitro resistance was not individually compared to in vivo resistance. On the other hand, standard techniques are not easily reproducible among the different scenarios in endemic areas, due to personnel, reagents laboratory conditions. Data from the same laboratories over time is more reliable information and may be used as a baseline for future further studies using the same technique. This paper presents preliminary data on the in vitro P. vivax resistance in the Western Amazon. More information is needed regarding the usefulness of this approach in detecting in vivo resistance and the association of more severe cases.

\section{Conclusion}

In summary, this study has shown that: 1) in vitro CQresistance estimated in this study was very similar to that obtained from clinical trials in the same area [17], suggesting that in vitro procedures developed by capable local laboratories are useful in the surveillance of the CQ-resistance in the Amazon; 2) P. vivax strains simultaneous resistance to both CQ and MQ within in the Amazon needs to be clarified; and 3) a non-synonymous mutation at pvdhps gene codon $382(\mathrm{~S} \rightarrow \mathrm{C})$ was associated to in vitro susceptibility to CQ.

The high levels of anti-malarial drug resistance in this region call for reinforced surveillance of drug efficacy. Plasmodium vivax CQ-resistance may be rising in the Brazilian Amazon and probably this fact is contributing to spread vivax malaria and clinical severity of this disease. However, the public health urgency to detect and measure the progression of CQ-resistant vivax malaria has been neglected. To maintain an efficient malaria control programme, drug resistance surveillance assays must be conducted on a regular basis to assess antimalarial efficacy and to ensure that the information is available to policy makers.

\section{Additional file}

Additional file 1: Oligonucleotide primers used for PCR amplification and DNA sequencing of Plasmodium vivax genes.

Competing interests

The authors declare that they have no competing interests. 


\section{Authors' contributions}

YFCM, MRFC, JSC, FN, LWB and GCM participated in laboratory procedures. YFCM, MRFC, MGCA, HS, WMM and MVGL participated in overall study conception and design, data collection, analysis, interpretation and manuscript preparation. All authors read and approved the final manuscript.

\section{Acknowledgements}

We acknowledge the collaboration of the local laboratory workers Maria José Siqueira da Costa and Elizângela Celestino. This study was supported by Conselho Nacional de Desenvolvimento Científico e Tecnológico (CNPq) (grant number 555666/2009-3) and by Fundação de Apoio à Pesquisa do Estado do Amazonas (FAPEAM) (grant number 1160/2010). MVGL has a Level 2 Productivity Fellowship from the National Council for Scientific and Technological Development (CNPq).

\section{Author details}

'Fundação de Medicina Tropical Dr. Heitor Vieira Dourado, Av. Pedro Teixeira, 25, Dom Pedro, Manaus, AM 69040-000, Brazil. ${ }^{2}$ Universidade do Estado do Amazonas, Av. Pedro Teixeira, 25, Dom Pedro, Manaus, AM 69040-000, Brazil. ${ }^{3}$ Centro de Malária e Outras Doenças Tropicais, UEl Malária, Instituto de Higiene e Medicina Tropical, Universidade Nova de Lisboa, Rua da Junqueira, 100, Lisbon 1349-008, Portugal. ${ }^{4}$ Universidade Nilton Lins, Av. Prof. Nilton Lins, 3259, Parque das Laranjeiras, Manaus, AM 69058-030, Brazil.

Received: 25 March 2013 Accepted: 24 June 2013

Published: 3 July 2013

\section{References}

1. Guerra CA, Howes RE, Patil AP, Gething PW, Van Boeckel TP, Temperley WH, Kabaria CW, Tatem AJ, Manh BH, Elyazar IR, Baird JK, Snow RW, Hay SI: The international limits and population at risk of Plasmodium vivax transmission in 2009. PLoS Negl Trop Dis 2010, 4:e774.

2. Oliveira-Ferreira J, Lacerda MV, Brasil P, Ladislau JL, Tauil PL, Daniel-Ribeiro CT: Malaria in Brazil: an overview. Malar J 2010, 9:115.

3. Lacerda MV, Mourao MP, Alexandre MA, Siqueira AM, Magalhaes BM Martinez-Espinosa FE, Filho FS, Brasil P, Ventura AM, Tada MS, Couto VS, Silva AR, Silva RS, Alecrim MG: Understanding the clinical spectrum of complicated Plasmodium vivax malaria: a systematic review on the contributions of the Brazilian literature. Malar J 2012, 11:12.

4. Price RN, Douglas NM, Anstey NM: New developments in Plasmodium vivax malaria: severe disease and the rise of chloroquine resistance. Curr Opin Infect Dis 2009, 22:430-435.

5. Alecrim MG, Alecrim W, Macedo V: Plasmodium vivax resistance to chloroquine (R2) and mefloquine (R3) in Brazilian Amazon region. Rev Soc Bras Med Trop 1999, 32:67-68.

6. Bray PG, Deed S, Fox E, Kalkanidis M, Mungthin M, Deady LW, Tilley L: Primaquine synergises the activity of chloroquine against chloroquineresistant $P$. falciparum. Biochem Pharmacol 2005, 70:1158-1166.

7. Powell RD, Berglund EM: Effects of chloroquine upon the maturation of asexual erythrocytic forms of Plasmodium vivax in vitro. Am J Trop Med Hyg 1974, 23:1007-1014

8. Tasanor O, Noedl H, Na-Bangchang K, Congpuong K, Sirichaisinthop J, Wernsdorfer WH: An in vitro system for assessing the sensitivity of Plasmodium vivax to chloroquine. Acta Trop 2002, 83:49-61.

9. Druilhe P, Brasseur P, Blanc C, Makler M: Improved assessment of Plasmodium vivax response to antimalarial drugs by a colorimetric double-site plasmodium lactate dehydrogenase antigen capture enzyme-linked immunosorbent assay. Antimicrob Agents Chemother 2007, 51:2112-2116.

10. Sharrock WW, Suwanarusk R, Lek-Uthai U, Edstein MD, Kosaisavee V, Travers T, Jaidee A, Sriprawat K, Price RN, Nosten F, Russell B: Plasmodium vivax trophozoites insensitive to chloroquine. Malar J 2008, 7:94.

11. Barnadas C, Ratsimbasoa A, Tichit M, Bouchier C, Jahevitra M, Picot S, Menard D: Plasmodium vivax resistance to chloroquine in Madagascar: clinical efficacy and polymorphisms in pvmdr1 and pvcrt-o genes. Antimicrob Agents Chemother 2008, 52:4233-4240.

12. Barnadas C, Musset L, Legrand E, Tichit M, Briolant S, Fusai T, Rogier C, Bouchier C, Picot S, Menard D: High prevalence and fixation of Plasmodium vivax dhfr/dhps mutations related to sulfadoxine/ pyrimethamine resistance in French Guiana. Am J Trop Med Hyg 2009, 81:19-22.
13. de Pecoulas PE, Tahar R, Ouatas T, Mazabraud A, Basco LK: Sequence variations in the Plasmodium vivax dihydrofolate reductase-thymidylate synthase gene and their relationship with pyrimethamine resistance. $\mathrm{Mol}$ Biochem Parasitol 1998, 92:265-273.

14. Hawkins VN, Joshi H, Rungsihirunrat $\mathrm{K}$, Na-Bangchang $\mathrm{K}$, Sibley $\mathrm{CH}$ : Antifolates can have a role in the treatment of Plasmodium vivax. Trends Parasitol 2007, 23:213-222.

15. Raj DK, Mu J, Jiang H, Kabat J, Singh S, Sullivan M, Fay MP, McCutchan TF, Su XZ: Disruption of a Plasmodium falciparum multidrug resistanceassociated protein (PfMRP) alters its fitness and transport of antimalarial drugs and glutathione. J Biol Chem 2009, 284:7687-7696.

16. Orjuela-Sanchez P, de Santana Filho FS, Machado-Lima A, Chehuan YF, Costa MR, Alecrim MG, del Portillo HA: Analysis of single-nucleotide polymorphisms in the crt-o and mdr1 genes of Plasmodium vivax among chloroquine-resistant isolates from the Brazilian Amazon region. Antimicrob Agents Chemother 2009, 53:3561-3564.

17. de Santana Filho FS, Arcanjo AR, Chehuan YM, Costa MR, Martinez-Espinosa FE, Vieira JL, Barbosa MG, Alecrim WD, Alecrim MG: Chloroquine-resistant Plasmodium vivax. Brazilian Amazon. Emerg Infect Dis 2007, 13:1125-1126.

18. Maguire JD, Krisin, Marwoto H, Richie TL, Fryauff DJ, Baird JK: Mefloquine is highly efficacious against chloroquine-resistant Plasmodium vivax malaria and Plasmodium falciparum malaria in Papua, Indonesia. Clin Infect Dis 2006, 42:1067-1072.

19. Ohrt C, Richie TL, Widjaja H, Shanks GD, Fitriadi J, Fryauff DJ, Handschin J, Tang D, Sandjaja B, Tjitra E, Hadiarso L, Watt G, Wignall FS: Mefloquine compared with doxycycline for the prophylaxis of malaria in Indonesian soldiers. A randomized, double-blind, placebo-controlled trial. Ann Intern Med 1997, 126:963-972.

20. Karwacki JJ, Webster HK, Limsomwong N, Shanks GD: Two cases of mefloquine resistant malaria in Thailand. Trans R Soc Trop Med Hyg 1989, 83:152-153.

21. Nomura T, Carlton JM, Baird JK, del Portillo HA, Fryauff DJ, Rathore D, Fidock DA, Su X, Collins WE, McCutchan TF, Wootton JC, Wellems TE: Evidence for different mechanisms of chloroquine resistance in 2 Plasmodium species that cause human malaria. J Infect Dis 2001, 183:1653-1661.

22. Nzila AM, Mberu EK, Sulo J, Dayo H, Winstanley PA, Sibley CH, Watkins WM: Towards an understanding of the mechanism of pyrimethaminesulfadoxine resistance in Plasmodium falciparum: genotyping of dihydrofolate reductase and dihydropteroate synthase of Kenyan parasites. Antimicrob Agents Chemother 2000, 44:991-996.

23. Lu F, Wang B, Cao J, Sattabongkot J, Zhou H, Zhu G, Kim K, Gao Q, Han ET: Prevalence of drug resistance-associated gene mutations in Plasmodium vivax in Central China. Korean J Parasitol 2012, 50:379-384.

24. Suwanarusk R, Russell B, Chavchich M, Chalfein F, Kenangalem E, Kosaisavee V, Prasetyorini B, Piera KA, Barends M, Brockman A, Lek-Uthai U, Anstey NM, Tjitra E, Nosten F, Cheng Q, Price RN: Chloroquine resistant Plasmodium vivax: in vitro characterisation and association with molecular polymorphisms. PLoS One 2007, 2:e1089.

25. Ranjitkar S, Schousboe ML, Thomsen TT, Adhikari M, Kapel CM, Bygbjerg IC, Alifrangis M: Prevalence of molecular markers of anti-malarial drug resistance in Plasmodium vivax and Plasmodium falciparum in two districts of Nepal. Malar J 2011, 10:75.

26. Picot S, Brega S, Gerome P, Velut G, de Monbrison F, Cheminel V, Peyron F: Absence of nucleotide polymorphism in a Plasmodium vivax multidrug resistance gene after failure of mefloquine prophylaxis in French Guyana. Trans R Soc Trop Med Hyg 2005, 99:234-237.

27. Sa JM, Nomura T, Neves J, Baird JK, Wellems TE, del Portillo HA: Plasmodium vivax: allele variants of the $\mathrm{mdr} 1$ gene do not associate with chloroquine resistance among isolates from Brazil, Papua, and monkey-adapted strains. Exp Parasitol 2005, 109:256-259.

doi:10.1186/1475-2875-12-226

Cite this article as: Chehuan et al: In vitro chloroquine resistance for Plasmodium vivax isolates from the Western Brazilian Amazon. Malaria Journal 2013 12:226. 